\title{
Viridicatumtoxin B, a new anti-MRSA agent from Penicillium sp. FR11
}

\author{
Chang-Ji Zheng, Hyung-Eun Yu, Eun-Hee Kim, Won-Gon Kim
}

Received: June 5, 2008 / Accepted: September 19, 2008

(C) Japan Antibiotics Research Association

\begin{abstract}
A new tetracycline-type antibiotic named viridicatumtoxin $\mathrm{B}$ along with the known compound viridicatumtoxin has been isolated from the mycelium of liquid fermentation cultures of Penicillium sp. FR11. The structure of viridicatumtoxin $\mathrm{B}$ was determined on the basis of MS and NMR data. Viridicatumtoxin B inhibited the growth of Staphylococcus aureus including methicillinresistant $S$. aureus and quinolone-resistant $S$. aureus with MIC $(\mu \mathrm{g} / \mathrm{ml})$ of 0.5 , which is similar with that of vancomycin, but $8 \sim 64$ times higher activity than that of tetracycline.
\end{abstract}

Keywords viridicatumtoxin B, tetracycline, Penicillium, antibacterial, MRSA

Gram-positive eubacteria are representative of pathogenic microorganisms. Especially, Staphylococcus aureus is the most clinically important of these pathogens because of its exceptional virulence, stress tolerance, and capacity to accumulate antimicrobial resistances [1]. Methicillinresistant S. aureus (MRSA) is known as a major nosocomial pathogen which has also developed resistance to many other antibiotics. Overall, in the United States and the United Kingdom, $40 \sim 60 \%$ of nosocomial $S$. aureus strains are methicillin-resistant. More deaths are associated with MRSA than with methicillin-sensitive strains. Moreover, MRSA has been reported to acquire resistance to the last-resort antibiotic, vancomycin [2]. Therefore, it is increasingly important and necessary to find new classes of antimicrobials.

In the course of our screening for new anti-MRSA agents from microbial resources, a new tetracycline-type antibiotic named viridicatumtoxin B (1) along with the known compound viridicatumtoxin (2) were isolated from liquid fermentation cultures of Penicillium sp. FR11 (Fig. 1). Compound $\mathbf{1}$ is a new epoxide derivative of viridicatumtoxin. Viridicatumtoxin is a tetracycline-type but rare metabolite, which has been once isolated from Penicillium viridicatum [3]. The antibacterial activity of viridicatumtoxin has not been reported. In this paper, we report the fermentation, isolation, structure determination, and antibacterial activity of $\mathbf{1}$ and $\mathbf{2}$.

\section{Fermentation and Isolation}

The fungal strain FR11 was isolated from a soil sample which was collected around Odae mountain, Kangwon-do, Korea, and identified as Penicillium sp. Fermentation was carried out in a liquid culture medium containing YPS medium $(2.0 \%$ glucose, $0.2 \%$ yeast extract, $0.5 \%$ peptone, $0.05 \% \mathrm{MgSO}_{4} \cdot 7 \mathrm{H}_{2} \mathrm{O}$, and $0.1 \% \mathrm{KH}_{2} \mathrm{PO}_{4}$, pH 5.7 before sterilization). A piece of the strain FR11 from a mature plate culture was inoculated into a 500-ml Erlenmeyer flask containing $80 \mathrm{ml}$ of the above sterile seed liquid medium and cultured on a rotary shaker $(150 \mathrm{rpm})$ at $28^{\circ} \mathrm{C}$ for 3 days. For the production of active compounds, $15 \mathrm{ml}$ of the seed culture were transferred into 1000-ml Erlenmeyer
W.-G. Kim (Corresponding author), C.-J. Zheng, H.-E. Yu: Korea Research Institute of Bioscience and Biotechnology, Yusong, Daejeon 305-806, Republic of Korea, E-mail: wgkim@kribb.re.kr
E.-H. Kim: Magnetic Resonance Team, Korea Basic Science Institute, Ochang, Cheongwon, Chungbuk 363-883, Korea 


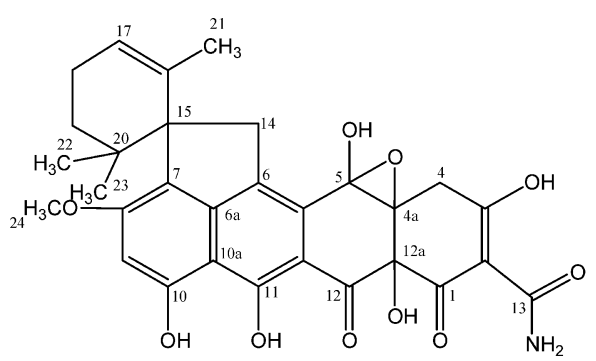

1<smiles>COc1cc(O)c2c3c1C(=C1C(=C2O)C(=O)[C@@]2(O)C(=O)C(C(N)=O)=C(O)C[C@]2(O)[C@H]1O)CC31C(C)=CCCC1(C)C</smiles>

2

Fig. 1 Structures of viridicatumtoxin B (1) and viridicatumtoxin (2).

flasks containing $300 \mathrm{ml}$ of the YPS medium, and cultivated on a rotary shaker $(150 \mathrm{rpm})$ for 7 days at $28^{\circ} \mathrm{C}$. After incubation, the fermented liquid cultures (20 liters) were extracted with $50 \% \mathrm{Me}_{2} \mathrm{CO}$. The $\mathrm{Me}_{2} \mathrm{CO}$ extracts was concentrated in vacuo to an aqueous solution, which was then extracted with an equal volume of EtOAc three times. The EtOAc extract (5.0 g) was subjected to ODS (YMC s$150 \mu \mathrm{m})$ column chromatography, followed by stepwise elution with $\mathrm{MeOH}: \mathrm{H}_{2} \mathrm{O}(50: 50,70: 30,80: 20,90: 10$, $100: 0)$. The active fractions eluted with both $\mathrm{MeOH}: \mathrm{H}_{2} \mathrm{O}$ $(80: 20)$ and $\mathrm{MeOH}: \mathrm{H}_{2} \mathrm{O}(90: 10)$ were pooled and concentrated in vacuo. The residue dissolved in $\mathrm{MeOH}$ was further purified by HPLC RP 18 reverse phase HPLC column $\left(20 \times 250 \mathrm{~mm}, \mathrm{YMC}_{18}\right)$ chromatography with a photodiode array detector. The column was eluted with $\mathrm{MeOH}: \mathrm{H}_{2} \mathrm{O}(85: 15)$ containing $0.01 \%$ trifluoroacetic acid at a flow rate of $5.0 \mathrm{ml} / \mathrm{minute}$ to afford $\mathbf{1}(2.0 \mathrm{mg})$ and $\mathbf{2}$ $(142.5 \mathrm{mg})$ at retention times of 32.1 and 38.2 minutes, respectively, as yellow powders.

\section{Structure Elucidation}

The ${ }^{1} \mathrm{H}$ - and ${ }^{13} \mathrm{C}$-NMR spectroscopic data of $\mathbf{2}$ suggested that this compound is a member of the tetracycline class. Independent interpretation of the ${ }^{1} \mathrm{H}$ - and ${ }^{13} \mathrm{C}$-NMR data together with the ${ }^{1} \mathrm{H}^{-}{ }^{1} \mathrm{H}$ COSY, DEPT, HMQC, HMBC NMR data led to the identification of $\mathbf{2}$ as viridicatumtoxin [4]. We found that the ${ }^{13} \mathrm{C}-\mathrm{NMR}$ chemical shifts at C-14 and $\mathrm{C}-19$ of viridicatumtoxin have been wrong assigned in the literature. Their ${ }^{13} \mathrm{C}$ chemical shifts should be revised.

The molecular formula of $\mathbf{1}$ was determined as $\mathrm{C}_{30} \mathrm{H}_{29} \mathrm{NO}_{10}$ on the basis of the HRESI-MS [ $(\mathrm{M}-\mathrm{H})^{-}$, $562.1711 \mathrm{~m} / \mathrm{z}(-0.2 \mathrm{mmu}$ error $)]$ in combination with the ${ }^{1} \mathrm{H}$ - and ${ }^{13} \mathrm{C}-\mathrm{NMR}$ data. Compound $\mathbf{1}$ gave characteristic UV maxima at 427 and $450 \mathrm{~nm}$, which were different from that of $\mathbf{2}(433 \mathrm{~nm})$ as shown in Table 1. IR absorptions of $\mathbf{1}$ at 1625 and $3417 \mathrm{~cm}^{-1}$ suggested the presence of carbonyl and hydroxyl moieties, respectively. The ${ }^{1} \mathrm{H}$ - and ${ }^{13} \mathrm{C}-\mathrm{NMR}$ data (Table 2) supported by the ${ }^{1} \mathrm{H}-{ }^{1} \mathrm{H}$ COSY, DEPT, and
Table 1 Physico-chemical properties of viridicatumtoxin B (1)

$\begin{array}{ll}\begin{array}{ll}\text { Appearance } \\ {[\alpha]_{D}^{25}}\end{array} & \begin{array}{l}\text { Yellow powder } \\ \text { ESI-MS }(\mathrm{m} / \mathrm{z})\end{array} \\ \text { HRESI-MS }(\mathrm{m} / \mathrm{z}) & 562\left[\mathrm{M}-\mathrm{M}-\mathrm{H}^{-}\right. \\ \quad \text { found. } & \\ \quad \text { calcd. } & 562.1711\left[\mathrm{M}-\mathrm{H}^{-}\right. \\ \text {Molecular formula } & 562.1713 \text { for } \mathrm{C}_{30} \mathrm{H}_{28} \mathrm{NO}_{10} \\ \text { UV } \lambda_{\max } \mathrm{nm}(\log \varepsilon)(\mathrm{MeOH}) & \mathrm{C}_{30} \mathrm{H}_{29} \mathrm{NO}_{10} \\ & 252(4.29), 289(4.32), \\ \mathrm{IR}(\mathrm{KBr}) \gamma \mathrm{cm}^{-1} & 427(3.92), 450(3.92) \\ & 3417,2923,2854,1625, \\ & 1588,1449,1399,1190\end{array}$

HMQC NMR data suggested the presence of an aromatic methine $(\delta 6.79, \mathrm{~s}, \delta 102.5)$, two isolated methylenes $\left(\delta_{\mathrm{H}}\right.$ $3.12, \mathrm{~d}, J=20.4 ; \delta_{\mathrm{H}} 2.84, \mathrm{~d}, J=20.4 ; \delta_{\mathrm{C}} 42.1$ and $\delta_{\mathrm{H}} 4.02$, $\left.\mathrm{d}, J=19.8 ; \delta_{\mathrm{H}} 3.01, \mathrm{~d}, J=19.8 ; \delta_{\mathrm{C}} 44.5\right)$, a methoxy, $-\mathrm{CH}(=)-\mathrm{CH}_{2}-\mathrm{CH}_{2}-$, two isolated methyls, an allylic methyl, five quaternary $s p^{3}$ carbons $(\delta 116.4,80.7,77.8$, 60.6 , and 38.4$)$, twelve quaternary $s p^{2}$ carbons ( $\delta$ 192.9, $165.3,161.2,158.4,146.0,144.8,135.7,127.2,116.9$, $106.8,106.6$, and 99.9), two ketone carbonyls ( $\delta 195.1$ and 188.6), and an amide carbonyl ( $\delta$ 172.9). These spectral data of $\mathbf{1}$ were similar to those of compound $\mathbf{2}$. The major difference between $\mathbf{1}$ and $\mathbf{2}$ in ${ }^{1} \mathrm{H}$ - and ${ }^{13} \mathrm{C}$-NMR data is that one quaternary $s p^{3}$ carbon ( $\left.\delta 116.4\right)$ was newly observed in $\mathbf{1}$ instead of the isolated hydroxy methine (C-5) in $\mathbf{2}$. In addition, the quaternary $s p^{2}$ carbons of C-4a and C-5a were downfield-shifted from $\delta 71.7$ and 137.3 to $\delta 77.8$ and 144.8 , respectively, while the quaternary $s p^{2}$ carbon of C-6 was upfield-shifted from $\delta 124.0$ and 116.9. These spectral data together with the molecular formula suggested that an epoxide could be formed between $\mathrm{C}-4 \mathrm{a}$ and $\mathrm{C}-5$. The presence of the epoxide moiety was determined by the HMBC spectrum (Fig. 2). One methylene proton at 2.84 
Table $2{ }^{1} \mathrm{H}$ - and ${ }^{13} \mathrm{C}-\mathrm{NMR}$ spectral data for $\mathbf{1}$ and viridicatumtoxin (2)

\begin{tabular}{|c|c|c|c|c|}
\hline \multirow{2}{*}{ Position } & \multicolumn{2}{|c|}{1} & \multicolumn{2}{|c|}{2} \\
\hline & $\delta_{\mathrm{H}}$ (mult., $\left.J_{\mathrm{HH}}\right)$ & $\delta_{\mathrm{C}}$ & $\delta_{\mathrm{H}}$ (mult., $\left.J_{H H}\right)$ & $\delta_{\mathrm{C}}$ \\
\hline 1 & & $188.6 \mathrm{C}$ & & $190.4 \mathrm{C}$ \\
\hline 2 & & $99.9 \mathrm{C}$ & & $99.8 \mathrm{C}$ \\
\hline 3 & & $192.9 \mathrm{C}$ & & $193.0 \mathrm{C}$ \\
\hline \multirow[t]{2}{*}{4} & Ha $2.84(1 \mathrm{H}, \mathrm{d}, 20.4)$ & $42.1 \mathrm{CH}_{2}$ & Ha $2.76(1 \mathrm{H}, \mathrm{d}, 19.0)$ & $40.5 \mathrm{CH}_{2}$ \\
\hline & Hb $3.12(1 \mathrm{H}, \mathrm{d}, 20.4)$ & & $\mathrm{Hb} 2.83(1 \mathrm{H}, \mathrm{d}, 19.0)$ & \\
\hline $4 a$ & & $77.8 \mathrm{C}$ & & $71.7 \mathrm{C}$ \\
\hline 5 & & $116.4 \mathrm{C}$ & $4.51(1 \mathrm{H}, \mathrm{s})$ & $71.9 \mathrm{CH}$ \\
\hline $5 a$ & & $144.8 \mathrm{C}$ & & $137.3 \mathrm{C}$ \\
\hline 6 & & $116.9 \mathrm{C}$ & & $124.0 \mathrm{C}$ \\
\hline $6 a$ & & $146.0 \mathrm{C}$ & & 147.3 C \\
\hline 7 & & $106.8 \mathrm{C}$ & & $105.9 \mathrm{C}$ \\
\hline 8 & & 161.2 C & & $161.0 \mathrm{C}$ \\
\hline 9 & $6.79(1 \mathrm{H}, \mathrm{s})$ & $102.5 \mathrm{CH}$ & $6.66(1 \mathrm{H}, \mathrm{s})$ & $100.0 \mathrm{CH}$ \\
\hline 10 & & $158.4 \mathrm{C}$ & & $158.2 \mathrm{C}$ \\
\hline $10 a$ & & $127.2 \mathrm{C}$ & & $122.9 \mathrm{C}$ \\
\hline 11 & & $165.3 \mathrm{C}$ & & $166.2 \mathrm{C}$ \\
\hline $11 a$ & & $106.6 \mathrm{C}$ & & $105.2 \mathrm{C}$ \\
\hline 12 & & $195.1 \mathrm{C}$ & & $195.5 \mathrm{C}$ \\
\hline $12 a$ & & $80.7 \mathrm{C}$ & & $80.4 \mathrm{C}$ \\
\hline 13 & & $172.9 \mathrm{C}$ & & $172.6 \mathrm{C}$ \\
\hline \multirow[t]{2}{*}{14} & Ha $3.01(1 \mathrm{H}, \mathrm{d}, 19.8)$ & $44.5 \mathrm{CH}_{2}$ & Ha $2.94(1 \mathrm{H}, \mathrm{d}, 17.4)$ & $41.4 \mathrm{CH}_{2}$ \\
\hline & Hb $4.02(1 \mathrm{H}, \mathrm{d}, 19.8)$ & & $\mathrm{Hb} 3.48(1 \mathrm{H}, \mathrm{d}, 17.4)$ & \\
\hline 15 & & $60.6 \mathrm{C}$ & & $60.1 \mathrm{C}$ \\
\hline 16 & & $135.7 \mathrm{C}$ & & $136.7 \mathrm{C}$ \\
\hline 17 & $5.52(1 \mathrm{H}, \mathrm{m})$ & $121.9 \mathrm{CH}$ & $5.51(1 \mathrm{H}, \mathrm{m})$ & $121.6 \mathrm{CH}$ \\
\hline \multirow[t]{2}{*}{18} & $\mathrm{Ha} 2.08(1 \mathrm{H}, \mathrm{m})$ & $22.8 \mathrm{CH}_{2}$ & $\mathrm{Ha} 2.21(1 \mathrm{H}, \mathrm{m})$ & $22.6 \mathrm{CH}_{2}$ \\
\hline & $\mathrm{Hb} 2.25(1 \mathrm{H}, \mathrm{m})$ & & $\mathrm{Hb} 2.24(1 \mathrm{H}, \mathrm{m})$ & \\
\hline \multirow[t]{2}{*}{19} & $\mathrm{Ha} 1.41(1 \mathrm{H}, \mathrm{m})$ & $34.1 \mathrm{CH}_{2}$ & Ha $1.35(1 \mathrm{H}, \mathrm{m})$ & $34.1 \mathrm{CH}_{2}$ \\
\hline & $\mathrm{Hb} 1.88(1 \mathrm{H}, \mathrm{m})$ & & $\mathrm{Hb} 1.85(1 \mathrm{H}, \mathrm{m})$ & \\
\hline 20 & & $38.4 \mathrm{C}$ & & $38.8 \mathrm{C}$ \\
\hline 21 & $1.46(3 \mathrm{H}, \mathrm{s})$ & $21.0 \mathrm{CH}_{3}$ & $1.53(3 \mathrm{H}, \mathrm{s})$ & $21.4 \mathrm{CH}_{3}$ \\
\hline 22 & $0.92(3 \mathrm{H}, \mathrm{s})$ & $24.3 \mathrm{CH}_{3}$ & $0.92(3 \mathrm{H}, \mathrm{s})$ & $24.2 \mathrm{CH}_{3}$ \\
\hline 23 & $0.46(3 \mathrm{H}, \mathrm{s})$ & $25.5 \mathrm{CH}_{3}$ & $0.48(3 \mathrm{H}, \mathrm{s})$ & $25.7 \mathrm{CH}_{3}$ \\
\hline 24 & $3.89(3 \mathrm{H}, \mathrm{s})$ & $55.7 \mathrm{CH}_{3}$ & $3.87(3 \mathrm{H}, \mathrm{s})$ & $55.7 \mathrm{CH}_{3}$ \\
\hline
\end{tabular}

${ }^{1} \mathrm{H}$ - and ${ }^{13} \mathrm{C}-\mathrm{NMR}$ spectral data were measured at 500 and $225 \mathrm{MHz}$, respectively, in $\mathrm{CDCl}_{3}$. The assignments were aided by ${ }^{1} \mathrm{H}-{ }^{1} \mathrm{H}$ COSY, DEPT, $\mathrm{HMOC}$, and $\mathrm{HMBC}$.

(Ha-4) was long-ranged coupled to the quaternary $s p^{2}$ carbons at $\delta 192.9(\mathrm{C}-3)$ and $99.9(\mathrm{C}-2)$, and the quaternary $s p^{3}$ carbons at $\delta 77.8(\mathrm{C}-4 \mathrm{a})$ and $80.7(\mathrm{C}-12 \mathrm{a})$. The other methylene proton at $3.12(\mathrm{Hb}-4)$ showed the HMBC correlations with the quaternary $s p^{2}$ carbon at C-3 and the quaternary $s p^{3}$ carbons at $\delta 116.4$ (C-5), indicating that the epoxide is present between $\mathrm{C}-4 \mathrm{a}$ and $\mathrm{C}-5$. The remaining structure was also confirmed by the HMBC spectroscopic data (Fig. 2) and the ${ }^{13} \mathrm{C}-\mathrm{NMR}$ data measured in $225 \mathrm{MHz}$
(Table 2). Thus, the structure of $\mathbf{1}$ was assigned as an epoxide derivative of viridicatumtoxin as shown in Fig. 1.

Compound 1 exhibited potent antibacterial activity against $S$. aureus (S. aureus RN4220 and S. aureus 503), methicillin-resistant S. aureus (S. aureus CCARM 3167 and $S$. aureus CCARM 3506), and quinolone-resistant $S$. aureus ( $S$. aureus CCARM 3505 and $S$. aureus CCARM $3519)$ with MIC $(\mu \mathrm{g} / \mathrm{ml})$ of 0.5 as shown in Table 3 . The antibacterial activity of $\mathbf{1}$ against $S$. aureus, MRSA, and 
quinolone-resistant $S$. aureus (QRSA) is similar with that of vancomycin, but $8 \sim 64$ times higher than that of tetracycline. Compound $\mathbf{1}$ also showed strong antibacterial activity against other pathogenic bacteria including Acinetobacter calcoaceticus, Enterococcus faecalis, and Streptococcus pneumoniae with MIC $(\mu \mathrm{g} / \mathrm{ml})$ of $1 \sim 2$. However, 1 didn't have antibacterial activity against some gram negative bacteria including E. coli, Pseudomonas

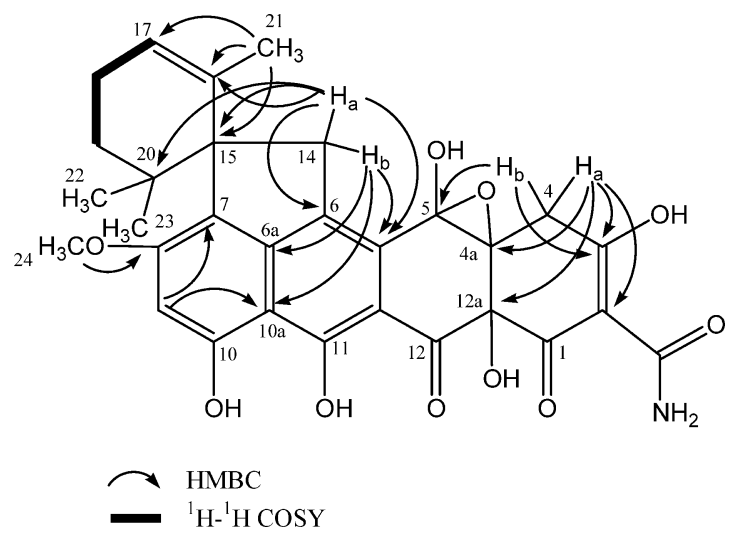

aeruginosa, and Klebsiella aerogenes like vancomycin, while tetracycline still showed potent activity on E. coli and Klebsiella aerogenes. The antibacterial potency and spectrum of $\mathbf{2}$ was similar with $\mathbf{1}$.

Compound $\mathbf{1}$ is a new epoxide derivative of viridicatumtoxin. Viridicatumtoxin is a tetracyclinetype metabolite which has been isolated from Penicillium viridicatum [3]. The absolute configuration of viridicatumtoxin has been determined by X-ray crystallographic methods [5]. The absolute configuration of compound 1 was not determined in this study because of a small amount. Viridicatumtoxin has been known to exhibit antitumor activity [4]. The antibacterial activity of viridicatumtoxin is reported for the first time in this study.

Compounds $\mathbf{1}$ and $\mathbf{2}$ showed potent antibacterial activity against several strains of $S$. aureus including MRSA and QRSA. They exhibited the similar activity with vancomycin, but $8 \sim 64$ times higher activity than tetracycline. Thus, these compounds may be useful for development of new anti-MRSA agents.

Fig. 2 Key $\mathrm{HMBC}$ and ${ }^{1} \mathrm{H}-{ }^{1} \mathrm{H}$ COSY correlations of $\mathbf{1}$.

Table 3 Antibacterial activity for $\mathbf{1}$ and $\mathbf{2}$ (MIC, $\mu \mathrm{g} / \mathrm{ml}$ )

\begin{tabular}{|c|c|c|c|c|}
\hline Test organisms & 1 & 2 & Tetracycline & Vancomycin \\
\hline Staphylococcus aureus 503 & 0.5 & 0.5 & 8 & 0.25 \\
\hline Staphylococcus aureus 209 & 0.5 & 0.25 & 4 & 0.25 \\
\hline Staphylococcus aureus RN4220 & 0.5 & 0.5 & 8 & 1 \\
\hline MRSA CCARM 3167 & 0.5 & 0.25 & 8 & 1 \\
\hline MRSA CCARM 3506 & 0.5 & 0.25 & 8 & 0.25 \\
\hline QRSA CCARM 3505 & 0.5 & 0.5 & 32 & 1 \\
\hline QRSA CCARM 3519 & 0.5 & 0.25 & 32 & 0.5 \\
\hline Bacillus subtilis КСТC 1021 & 0.06 & 0.06 & 0.03 & 0.12 \\
\hline Bacillus cerues KCTC 1661 & 8 & 16 & 0.25 & $>64$ \\
\hline Micrococcus luteus KCTC 1056 & 0.12 & 0.12 & 0.06 & 0.06 \\
\hline Streptococcus pneumoniae KCTC 3932 & 1 & 2 & 0.5 & 0.25 \\
\hline Streptococcus pneumoiae KCTC 5412 & 2 & 2 & 0.25 & 0.25 \\
\hline Entercoccus faecium KCTC 3122 & 0.5 & 1 & 0.25 & 1 \\
\hline Entercoccus faecalis KCTC 5191 & 2 & 4 & 0.06 & 1 \\
\hline Entercoccus faecalis KCTC 3511 & 2 & 4 & 8 & 2 \\
\hline Staphycococcus epidermidis KCTC 3958 & 0.25 & 0.25 & 0.5 & 1 \\
\hline Salmonella typhinurium KCTC 1926 & 8 & 8 & 0.25 & 32 \\
\hline Acinetobacter calcoaceticus KCTC 2357 & 1 & 2 & 0.06 & 1 \\
\hline Escherichia coli CCARM 1356 & $>64$ & $>64$ & 0.5 & 64 \\
\hline Escherichia coli KCTC1682 & $>64$ & $>64$ & 0.25 & $>64$ \\
\hline Pseudomonas aeruginosa KCTC 2004 & $>64$ & $>64$ & 8 & $>64$ \\
\hline Pseudomonas aeruginosa KCTC 2742 & $>64$ & $>64$ & 16 & $>64$ \\
\hline Klebsiella aerogenes KCTC 2619 & $>64$ & $>64$ & 0.5 & $>64$ \\
\hline Candida albicans KCTC 7535 & $>64$ & $>64$ & 2 & 32 \\
\hline
\end{tabular}


Acknowledgments This work was supported by the $21 \mathrm{C}$ Frontier Microbial Genomics and Application Center Program (Grant MG08-0304-2-0), Ministry of Science and Technology, Republic of Korea.

\section{References}

1. Levy SB, Marshall B. Antibacterial resistance worldwide: causes, challenges and responses. Nat Med 10: S122-S129 (2004)

2. Pfeltz RF, Wilkinson BJ. The escalating challenge of vancomycin resistance in Staphylococcus aureus. Curr Drug Targets-Infect Disord 4: 273-294 (2004)

3. Hutchison RD, Steyn PS, Van Rensburg SJ.
Viridicatumtoxin, a new mycotoxin from Penicillium viridicatum Westling. Toxicol Appl Pharmacol 24: 507-509 (1973)

4. Raju MS, Wu GS, Gard A, Rosazza JP. Microbial transformation of natural antitumor agents. 20 . Glucosylation of viridicatumtoxin. J Nat Prod 45: 321-327 (1982)

5. Silverton JV, Kabuto C, Akiyama T. The structure and absolute configuration of viridicatumtoxin: $2^{\prime} S$ $\left(2^{\prime} \alpha, 7^{\prime} \alpha \beta, 11^{\prime} \alpha \beta, 12^{\prime} \beta\right)-7^{\prime}, 7^{\prime} \mathrm{a}, 8^{\prime}, 11^{\prime}, 11^{\prime} \mathrm{a}, 12^{\prime}$-hexahydro$5^{\prime}, 6^{\prime}, 7^{\prime}$ a $, 10^{\prime}, 11^{\prime}$ a, $12^{\prime}$-hexahydroxy-3'-methoxy-2, 6,6trimethyl-7', 8' -dioxospiro[2-cyclohexene-1,2' (1'H)cyclopenta[de]naphthacene]-9'-carboxamide methanolate. Acta Cryst B38: 3032-3037 (1982) 